SCIENTIFIC REPORTS

\title{
Personal branding through leadership
}

\section{Milovanovic Svetislav ${ }^{18}$, Baltazarevic Borivoje ${ }^{19}$, Milovanovic Nina ${ }^{20}$}

\begin{abstract}
The main idea of this study is to demonstrate that leadership is increasingly becoming an important and current global phenomenon known as personal branding. Leadership is of utmost importance for each human activity, and even for the entire progress of humanity which has always moved forward thanks to people and, naturally, great endeavors of great people. Leadership is what makes the world go round. Although a personal branding investigated in terms of defining, describing various practices and the growing importance of the use of these techniques, there is still a gap in the scientific literature regarding how technology advancement in the business to take advantage of the positioning of the individual in the global market. Therefore, the primary objective of this paper provide new insights into the personal branding that will be useful for the academic community and provide conclusions for its practical application in entrepreneurship.
\end{abstract}

KEY WORDS: leadership, human activity, personal branding, literature

JEL: M12, M13

UDC: 005.322:316.46

COBISS.SR-ID 219520012

\footnotetext{
${ }^{18}$ Corresponding author, Institucija d.o.o. Belgrade, e-mail: sv.milovanovic@institution.rs

${ }^{19}$ Faculty of Culture and Media, Megatrend University, Belgrade, e-mail: baltezb@yahoo.co.uk

${ }^{20}$ Faculty of Culture and Media, Megatrend University, Belgrade, e-mail: muzejrata@gmail.com
} 


\section{Personal brend}

Personal branding is to the fore in article A Brand Called You in Fast Company magazine, which in 1997 wrote Tom Peters, and often (the last few years) considered the phenomenon of American society in which the prevailing individualistic culture. With the recent global economic crisis, which has hit many developed countries, personal branding has come into its own through the action of various professionals who are striving to obtain and/or maintain their current position, demonstrated through self rending what their potential in terms of values, skills and the knowledge that they are able to offer to the company that employs them (or will only employ). Thus, personal branding is used to promote what the man has to offer the business, clients, customers, or any other aspect of life, depending on their goals and objectives. Known managers use personal branding to expand its core competencies in various business ventures that it is extremely rich in the financial sense, but also in terms of power, prestige and influence they have on the global level.

Some theorists describe a personal branding strategy to promote you in the business world, which is not new; however, the scope of personal branding has grown from a simple business tactic in psychological recognition of the impact that the business world has the ideas and the awareness of individuals about the itself.

Exploration of market leader's personal branding is growing in the field of management, marketing and organizational behavior research market. The popularity of the personal brand among practitioners and marketing professionals, as well as scientists, shows the need for a better, deeper understanding of personal branding and its use of practical and academic perspective.

Personal branding as a process of identification and exploitation of strategic resources in entrepreneurial ventures brings benefits with using personal branding for promotion with its entrepreneurial business objectives.

Today's opinion that without brand product does not exist, leads to branding cities, countries, universities (Kavaratzis, 2005).

Using brands for people has developed into a growing construct branding, although it has very little support in the academic literature. Personal branding is increasingly common phenomenon for decades used in various aspects, for entertainers, athletes, authors, general managers, business owners and politicians, and has spread too many other people in different positions in the company. Entrepreneurs using personal branding when they are trying to set up a credible and trusted resource in their industry, and then promote and sell their products and services, as an extension of the credibility and reliability.

Theory of branding tends to define brand identity as an internal structure that emerges from the unilateral view of the organization (what brand managers want to be) that requires stability (Aaker, 1996; Kapferer, 2008). Consequently, the brand manager needs to develop and maintain a clear and consistent identity, so that brands can serve as a stable reference for consumers (Aaker, 1996; Kapferer, 2008). The widespread opinion is that a stable brand identity can assist companies in navigating and adapting to market changes (Collins and Porras, 1994). In practice, in accordance with this principle, companies tend to stabilize the identity of their brands over time. However, the environment is becoming more dynamic and many market segments experiencing unexpected mutation and unpredictable transformation. Proactive participation of consumers requires consumers participation in the process of value creation, where consumers are active contributors (Arnould and Thomson, 2005; Brown, Kozinets and Sherry, 2003; Payne, at al. 2009). Such challenges require new insights into the conceptualization of brand identity. 
Definition of branded leaders (managers) given by Senge, (1990, p.229) has five disciplines of personal skills that include an explanation of loyalty correctness, decisionmaking power and infrastructure innovations that enhance personal and interpersonal skills. Although based on competencies and skills, personal brand goes beyond competence and skills. Exceeds the spirituality and openness, although requires spiritual development. It means access to one's life through creative work, living life based on a creative point of view, which is contradictory to reactive a viewpoint. Leaders with high-constructed personal brand will create better links between companies and consumers, companies and employees and promote the development and position their organizations. For the personal branding very important are: integrity, wisdom, knowledge, empathy, perseverance and self awareness.

Personality can be defined as a person's profile or a combination of natural features and uniqueness and their interactions with others. In short, the figure is a combination of a set of one's physical and mental characteristics. There are a number of outlook figures, whether they can be permanent or developed; whether they are innate or can be shaped by experience (Yukl, 2005, p.231-232).

\section{Characteristics of a leader}

When we talking about leaders, it is always about that part of their personality which concerns the way they rule over others, persuade them, effect and lead them. Naturally, it also always has to do with the way they control themselves, keep themselves in hand and discipline themselves. It has to do with the manner in which they think, the speed with which they make decisions, the education and expertise they possess: many things are important. Still, the most important aspect is certainly their personality - what we would call character. There is a well-known saying that 'character is destiny'. It relates to the set of characteristics which a person has and which he can influence only through a great strength of will. They are the traits one is born with and which, as we often think, determine us forever. What is certain, however, is that everyone bears some respond- suability for the formation of their own character. Although it is true that much depends on genetics, place of birth, social conditions, family background, education, the milieu and general circumstances such as the political moment and the prevailing ideology, the model of behaving and thinking adopted in childhood and youth, as well as a whole series of similar external factors more or less favorable to the development of an individual - still much depends on the person alone.

Everyone in the world, regardless of the circumstances in which they were born and raised, is presented with certain life opportunities, which they can either seize, or not. The decisions they make, or, indeed, whether they make them at all or allow themselves to be carried by the currents of life through uncertainty of random situations, depend on the strength of their will. Moreover, it depends on whether they will follow through on the decisions they made, whether they will make the right life choices, in what way they will live up to the promises they made to themselves - all of it is determined by their character. But, what is character? Many agree that character traits are actually habits. What does this mean? This means that it is possible to become a leader, regardless of age, education and what one actually is at any given time. 
It is possible to become a leader if one makes up their mind to it. It is possible to change one's own character since it is possible to make up for past mistakes. It is, at least, possible to decide to stop making mistakes in future. One thing is certain, though: without strong will, there is no leader. It is possible to change one- self through the power of will. This is why the one who is able to motivate him will be able to lead others. He, who cannot rule himself, cannot rule others and stand at their head. If character is indeed a force of habit, this can be of utmost importance for individuals who aspire to become leaders. It is rooted in the possibility of self-initiative. It is actually possible to overcome and compensate for things missed in childhood and early youth. It is actually possible to develop self-discipline which has not been encouraged in continuity and turn things around. It is certainly possible to achieve this during the period of psycho-physical maturity.

A man who has free will can always change his habits, and consequently his character. All earlier omissions mostly concern a certain body of knowledge and skills which have not been properly mastered. This directly means that it is possible for someone who has always been a 'loser' to become a 'winner'. A person is given an opportunity to control himself and affect his own behavior. If there are no obstacles in terms of motivation, if thinking is not tainted with pessimism and if one can master his own attention, anything is possible. When we focus on the goal, stop wasting energy and attention on the peripheral, but direct it to the essence, when this becomes a behavioral pattern, we may even not need to master leadership techniques at all. Mastering one's own character and controlling oneself are the most important preconditions for becoming a leader. This road may even ultimately prove to be superior. It leads to the best version of oneself and is therefore more difficult. This is why once a person attains a conscious command over himself, he knows forever what, how and why he does something. There is something to be said for spontaneous, so-called 'innate' behavior, but once a man masters this skill, he becomes a sovereign forever; he will always remain aware and strong. Consequently, a man who does not lack willpower, and possesses will for power, is a leader! A psychiatric paradigm is only one of many theoretical approaches and only one of the branches of medicine which touch upon everyday life, influencing the rules of human communication in the contemporary society.

The phenomenon of leadership is often identified with intelligence and tendency to avoid making mistakes, or is seen as a sense of realism. It is, however, certain that because of the exceptional creativity which leaders must possess, there also has to be certain irrational behavior in them, such behavior inherent in mentally sane persons. This is the same irrationality that easily multiplies and spreads, and is conveyed to social groups and mass movements by the energy charge of the leader. The mental capacity of a leader comprises more than just cognitive abilities (logical deduction, perceptive cognition, memorizing important bits of knowledge), but also the ability to emotionally experience a significant amount of life situations. It is particularly important that leaders control their own behavior that they persevere in certain intentions, and above all that their mental activities and processes are in synchrony.

A basic presumption is that a leader will not display even the slightest feebleness of will, because he possesses all those mental qualities that enable rational action. It is implied that he as a personality will exploit his knowledge and freedom more than anything else, and these will prevent him from getting into a state of inner or outer non-freedom because of an omission in a certain situation. Naturally, the way the personality of a leader is formed depends on a number of factors. 
Responsibility is not only on his personality - it will also be affected by the overall social context, the culture he was raised in, including his upbringing in the earliest age and other people from his immediate and broader environment.

Even the political system can sometimes generate a behavioral pattern typical for leaders. This has occurred throughout history, most often in a time of great leaders when individuals felt an urge to outgrow their peers and be worthy of their leaders, while in large groups it even came to a »growing of the nation«. Today, unfortunately, the system promotes unattainable values and citizens are often faced with unrealistic demands, and this creates a traumatic psychological gap between individuals. In short, it can be said that there are systems which encourage leadership and those that break it down.

\section{Personal branding as a complex phenomenon}

Despite its simple message - control our own image is a means of controlling one's social capital - personal branding is a very complex phenomenon, which relies on three aspects of logic that stems from the historical context. First, personal branding has inherited a long-standing scientific management technique that Deleuze (1992) calls 'fortune'. In his work "About the societies of control", Deleuze opposes what he calls, 'society of control' and concept of disciplined societies. While disciplined society moves intermittently from area to area (school, home, work), and is, therefore, described over and overweight individuals that were formed and re-formed in this region, the current, 'society of control' deals with what Deleuze called,'individual'. 'Individual' are infinitely divisible collection of data on subjects that can be extracted and manipulated through space and time. In this mode, the corporation does not deal with discrete areas of production, such as factories, but market shares and floating currencies.

All these continuous control and data collection fragmenting self on the data, and they are reinforced by the Internet. As Robert Williams (2005) argues, 'because I'm not physically present, I reduced my documented interests and behavior'. Complex process of self formatting is thus objectified with a few formulas and data points into an electronic storage. Personal branding theorists recognized in terms of what Eva Ilouz (2007) call 'emotional capitalism'. Capitalism is a culture in which emotional and economic discourses and practices mutually shape each other, producing what we see as a broad, sweeping movement in which he made an essential aspect of economic behavior in which emotional life-especially the middle class follows the logic of economic relations and trade. To investigate this, Ilouz follows the rationalization of emotions in the American mind of the twentieth century. She argues that the seemingly immeasurable emotions actually made quantifying and thus proportional to technology and techniques of post-Freudian psychotherapy.

Emotions, which she defined as ,'internal energy that move us toward actions' are guided by ,'therapeutic discourse' to supply the employers and company new tools for managing employees (Ilouz, 2007). She believes that the decision of the capitalism went hand in hand with the creation of intensive specialized emotional culture. Similar to Deleuze's control society, Ilouz focuses on corporate use of emotional exchange in the regulation of labor. However, personal branding is an individual reaction to this form of regulation; personally branded deliberately engage in emotional exchange, in order to get the benefits, and build their own capital. Branded adopted 'manage the self' as a new discipline. 
Finally, advocates and supporters of personal branding are recognized, internalized, and seek to benefit from what Andrejevic called, 'controlled economy" (Andrejevic, 2007; 2003). Noting the new trend 'reality TV' Andrejevic claims that society have started with an era where we see each other within the limits of digital broadcasts, hoping to gain control over the production of media objects; if we are willing to expose our private lives to the public through surveillance mechanisms, we can influence the course of the mass media to shape them inside. Personal branding relies on this logic, but it is also changing, engaging in the ,'self-monitoring'. Personally branded are particularly interested in its image and perception of other people in this image. All look at each other (and marketing and corporate watch all of us), and personally branded decided to continuously monitor and supervise its image in an attempt to control the experience (Andrejevic,2007). Thus, while most simply uses the network for collecting information, connecting with acquaintances and checking bank accounts-under the scrutiny of the new media and marketing capitalpersonally branded adopted three-part logic of scientific management in the form of emotional capitalism, and control economy requires a new network connection .

\section{Conclusion}

Our personal brands are the most valuable asset that we have and they are more valuable than the real estate. The goal of personal branding is to create a high marketing image, visible in the competition. The trend of personal branding is born from a combination of leadership theory and the theory of branding, combining the best of both.

The thing is that it is obvious that leadership is most certainly the strongest and the most delicate branch of the contemporary life. It is so all-encompassing; it permeates the world of today to such an extent that we must treat leadership with utmost caution. Leaders are those who lead us and who will take us to our goal.

What this goal is, which leader we will follow, where he will lead us and how - this is an extremely important and big question.

Growing interest in emotion softens the boundaries between the company and personal branding, especially in the concept of emotional intelligence, which from the sphere of science and psychology slowly becomes management discipline.

Personal branding is the process where people and their careers are viewed as a brand. Personal brand makes different person than the competition and gives personality management/leadership position.

Distinctive and positive image of a particular personal brand represents a significant advantage in the successful positioning of a new product on the global market.

Branding people require more than just charts and research. It's a branding live, breathing and volatile person who can change his mind in the half of the process. In traditional branding products apply the traditional tools for branding, primarily to the product or service to provide value and financial benefits for the company to which it belongs. 


\section{References}

[1] Aaker, D. (1996). Building Strong Brands, http://www.haas.berkeley.edu

[2] Andrejevic, M. (2003). "Tracing Space: Monitored Mobility in the Era of Mass Customization," Space and Culture, 6(2) 132-150.

[3] Andrejevic, M. (2007). iSpy: Surveillance and Power in the Interactive Era, University Press of Kansas

[4] Arnould, Eric J., Craig J. Thompson (2005). "Consumer Culture Theory (CCT): Twenty Years of Research," Journal of Consumer Research, 31 (March), 868-82.

[5] Brown, Stephen, Kozinets, Robert V.,Sherry Jr.(2003): Teaching Old Brands New Tricks: Retro BfaiKting and the Revival of Brand Meaning, Journal of Marketing Vol. 67,p.19-33.

[6] Collins, James C.,Jerry I. Porras (1994). Built to Last: Successful Habits of Visionary Companies, New York: HarperBusiness

[7] Deleuze, Gilles (1992). "Postscript on the societies of control," October, volume 59, pp. 3-7.

[8] Illouz, E. (2007). Cold Intimacies: The Making of Emotional Capitalism. Oxford, and Malden, MA: Polity Press

[9] Kavaratzis M, (2005). Place Branding: A Review of Trends and Conceptual Models, The Marketing Review, Vol. 5, No. 4, pp. 329-342

[10] Kapferer, Jean-Noël (2008). The New Strategic Brand Management: Creating and Sustaining Brand Equity Long Term, Kogan Page Publishers.

[11] Payne A, Storbacka K, Frow P, Knox S. (2009). Co-creating brands: diagnosing and designing the relationship experience. J Bus Res 2009;62(3):379-89.

[12] Senge, P. (1990). The Fifth Discipline, Doubleday, New York, NY.

[13] Yukl, G. (2005). The leadership in organizations. New Jersey: Pearson Higher Education.

[14] Williams W. R.( 2005). "Politics and self in the age of digital re(pro)ducibility," Fast Capitalism, volume 1, number 1 , at http://www.uta.edu/huma/agger/fastcapitalism/1_1/williams.html

\section{Article history:}

- $\quad$ Received 8 September 2015

- $\quad$ Accepted 2 November 2015 